III. Aus dem Institut für Infectionskrankheiten in Berlin. (Director: Geh. Med.-Rath Prof. Dr. R. Koch.)

\title{
Experimentelle Beiträge zur Serumtherapie vermittels antitoxisch und bactericid wirkender Serumarten.
}

Von Dr. A. Wassermann, Assistenten am Institut.

Die Serumtherapie hat sich seit der Entdeckung Behring's eine der Hauptstellen auf dem neueren Forschungsgebiete der Medicin erobert, und, wie wir sagen können, mit vollem Recht. Denn heute, wo die specifisch-therapeutische Kraft des Diphtherieserums fast von allen Seiten anerkannt ist, können wir erst den Fortschritt, den diese neue Heilmethode bedeutet, an der Hand von grossen Zahlenreihen beurtheilen. Dass eine derartige wissenschaftliche That einen gewaltigen Einfluss auf die Forschungsrichtung ausübt, ist nicht wunderbar. - In der That sehen wir denn auch in der medicinischen Litteratur und vorzüglich in der Disciplin der Infectionskrankheiten seit dieser Zeit die therapeutischen Bestrebungen im Vordergrunde. Schon der Entdecker der Serumtherapie, Behring, hatte ja erkannt, dass die von ihm festgestellte Schutzkraft des Immunserums nicht nur für die zuerst näher untersuchten Affectionen Geltung habe, sondern dass wir es hier mit einem weit verbreiteten biologischen Gesetze zu thun haben. Es lag nun nichts näher, als nach dem Schema der Tetanus- und Diphtherieimmunität Thiere gegen andere Bacterienarten zu immunisiren und deren Serum in Bezug auf Schutz und Heilung im Experiment zu versuchen. Dies war um so leichter zu bewerkstelligen, als sich unsere Kenntnisse über dis Erzielung der künstlichen Immunität im Verlaufe der Forschungen von Behring, Ehrlich, R. Pfeiffer u. a. sehr erweitert hatten. Es zeigte sich bald, dass die Erzielung eines gewissen Grades von Immunität bei manchen Affectionen, wie Typhus, Cholera, Pyocyaneus sich sogar sehr viel rascher und leichter als bei den von Behring zuerst in das Experiment gezogenen erreichen lässt.

Speciell für manche, besonders in der menschlichen Pathologie wichtige Infectionen, wie Cholera, konnte frühzeitig nachgewiesen werden, dass selbst eine einmalige specifische Reaction, sei sie nun durch lebende oder todte Bacterien hervorgerufen, genügt, um Thieren einen gewissen Grad von Schutz gegenüber den lebenden Infectionserregern zu verleihen. Kurz, es bildete sich rasch eine Art Immunisirungsschema heraus, nach welchem nun Thiere und Menschen mit den verschiedensten, theils lebenden, theils todten Bacterienarten vorbehandelt wurden, um ihrem Serum schützende Eigenschaften zu verleihen. Das wesentliche dabei bestand, wie ich an anderer Stelle bereits auszuführen Gelegenheit hatte, $\left.{ }^{1}\right)$ darin, nach dem Muster der Behring-Ehrlich'schen Giftimmunisirung steigende Mengen des Substrates, gegen das geschützt werden sollte, dem betreffenden Organismus einzuverleiben, um auf diese Weise den durch die erste Injection geschaffenen geringeren Grad von Immunität (Ehrlich's "Grundimmunität") mittels der nachfolgenden, in der Dose stets stärker werdenden, in die Höhe zu treiben.

Mit Hülfe dieses Verfahrens gelang es, die Behring'sche Entdeckung von der Schutzkraft des Serums derart immunisirter Thiere auf eine Reihe von anderen Infectionserregern, wie besonders Typhus- und Cholerabacillen auszudehnen. Mit diesen Serumsorten wurden dann weiterhin, allerdings in kleinerem Maasse, Versuche an erkrankten Menschen angestellt, indessen ohne auch nur annähernd den günstigen Erfolg, wie mit dem Diphtherieheilserum zu erzielen. Diese anfangs gewiss auffallende Thatsache wurde unserem Verständniss nähergerückt durch die Befunde R. Pfeiffer's. Der genannte Forscher konnte nämlich einen tiefgreifenden Unterschied des bis heute am Menschen zur Heilung verwendeten Typhus-, und Choleraserums gegenüber dem Behring'schen Tetanus- und Diphtherieheilserum nachweisen. Dieser besteht darin, dass die letzteren Serumarten imstande sind, auf die von den Tetanus-, resp. Diphtheriebacillen ausgeschiedenen Gifte zu wirken, während das von R. Pfeiffer untersuchte Cholera-

1) Zeitschrift für Hygiene und Infectionskrankheiten Bd. XXII. 
und Typhusserum die lebenden Cholera-, resp. Typhusbacillen im Organismus abzutödten, nicht aber die nach diesem Forscher in den abgetödteten Bacterien dann noch enthaltenen Gifte zu beeinflussen vermag. Seit diesen Arbeiten besteht die scharfe Trennung zwischen den antitoxisch, das heisst auf die Gifte, und den bactericid, das heisst auf die lebenden Bacterien wirkenden Serumarten.

Betreffs der Einzelheiten hierüber und des näheren Zusammenhanges dieser verschiedenen Wirkungsweise des Immunserums kann ich hier der Kürze halber auf eine vorhergehende Arbeit ${ }^{1}$ ) verweisen.

Wir sehen also, dass bei der specifischen Heilung der meisten Infectionskrankheiten die Beeinflussung zweier ätiologischer Factoren in Frage kommt. Es sind das einmal die in den Organismus eingedrungenen lebenden Krankheitskeime, und zweitens die von ihnen gebildeten, resp. in ihnen enthaltenen Gifte, deren grosse Wichtigkeit für die Pathologie hauptsächlich Brieger in zahlreichen Arbeiten dargethan hat.

Die wichtige Rolle, welche gerade die letzteren auch für jede zu erreichende specifische Therapie der Infectionskrankheiten spielen, hatte Behring von vornherein bei seinen Versuchen erkannt, sein Hauptbestreben war daher von Anbeginn an darauf gerichtet, bei Tetanus und Diphtherie die Gifte im Organismus zu zerstören, also antitoxische Kräfte im Immunserum zu erhalten. Behring ging dabei von der Ansicht aus, dass nach Unschädlichmachung der Toxine die natürlichen Abwehrkräfte des Organismus instande seien, die noch in ihm verbleibenden lebenden Infectionserreger ohne unsere weitere Hülfe zu beseitigen. Der Erfolg hat die Richtigkeit dieser Ansicht für Tetanus und Diphtherie bestätigt, indem sich in der That zeigte, dass die antitoxischen Sera gleichzeitig auch gegenüber den lebenden Infectionserregern heilend wirken. Ich konnte run an dem Beispiele des Bacillus pyocyaneus nachweisen, dass man hier imstande ist, je nach dem Vorgange des Immunisirens im Serum antitoxische oder rein bactericide Kräfte zu erhalten, dabei aber die Thatsache constatiren, dass, sobald das Serum gegen das Gift wirksam war, es stets auch gegenüber den lebenden Keimen Schutz gewährte, wie wir dies vom antitoxischen Tetanus- und Diphtherieserum wissen. Andererseits dagegen schützt das Pyocyaneusserum, das rein bactericid, also gegenüber den lebenden Keimen wirksam ist, damit nicht gegen das Gift. Es schien mir nun interessant, mit Hülfe dieser beiden biologisch verschiedenen Serumarten Heilversuche an Thieren gegenüber der Intoxication und Infection mit Pyocyaneus anzustellen.

Der erste, welcher auf diesem Gebiete experimentell exacte Heilversuche unternahm, war Behring. Derselbe nahm mit seinen Mitarbeitern Wernicke, Boer und Knorr Heilversuche gegen specifische Bacteriengifte, nämlich das Tetanus- und Diphtheriegift, an Thieren in Angriff. Unter den vielfachen wichtigen Resultaten, die aus diesen Experimenten hervorgingen, ist besonders ein Punkt für die gesammte Serumtherapie maassgebend geworden.

Es ist dies die Thatsache, dass zur Heilung von einer gewissen Giftdose ungleich grössere Mengen Antitoxin nöthig sind als zum vorherigen Schutze gegen dieselbe Giftmenge und dass, je später nach der Intoxication oder Infection die Behandlung hegonnen wird, desto grössere Serummengen erforderlich sind, um das Thier noch zu retten, bis endlich ein Stadium der Vergiftung eintritt, bei dem es mit den bisher erzielten Antitoxingraden überhaupt nicht mehr gelingt, das Leben zu erhalten.

Der Spannraum, innerhalb dessen nach erfolgter Vergiftung. bei Diphtherie im Thierexperiment Heilungserfolge noch erzielt werden können, ist nach den oben citirten Arbeiten ein recht grosser. Die Thiere können bereits sehr ausgesprochene und vorgeschrittene Symptome der Krankheit bieten, und trotzdem ist ihre Rettung bei genügender Antitoxinzufuhr noch möglich.

Wie verhält sich aber nun bis jetzt im Thierexperiment diese Heilungsmöglichkeit bei anderen Krankheiten, insbesondere bei solchen, bei denen weniger die Beeinflussung der Gifte, als vielmehr die Beseitigung der lebenden Krankheitserreger im Vordergrunde steht? Es sind das also die Fälle, in denen die bactericiden Körper des Immunserums in Thätigkeit treten. Aus der Reihe dieser Krankheiten ist vornehmlich die bei Meerschweinchen nach der intraperitonealen Einverleibung der lebenden Choleravibrionen auftretende Affection experimentell studirt worden. Bekanntlich vermehren sich nach einer genügend starken Infection die Choleravibrionen in der Bauchhöhle von Meerschweinchen sehr stark und führen acut den Tod der Thiere herbei. In den Leichen findet man alsdann massenhaft lebende Vibrionen. Untersucht man nun Serum von Menschen, die kurz vorher Cholera überstanden haben, oder von Thieren, welche mittels Choleraculturen künstlich immunisirt wurden, so zeigt es sich, dass dieses die Fähigkeit hat, Meersclıweinchen gegen eine starke Cholerainfection zu schützen. Ja,

1) a. a. 0 . es sind zu diesem Zwecke nur minimale Quantitäten Immunseruin nöthig, so dass es beispielsweise R. P feiffer gelungen ist, Thiere soweit in der Immunität gegen Cholera hochzutreiben, dass Bruchtheile eines Milligramms von ihrem Serum genügten, um andere Thiere vor der Infection $\mathrm{zu}$ bewahren. Die Vibrionen gehen unter diesen Umständen sofort im Organismus zugrunde, wie R. Pfeiffer demonstriren konnte. Inficirt man nun aber vorher ein Thier mit einer genügend starken Dose Cholera und stellt dann mit diesem Serum einige Zeit nach der Infection Heilversuche an, so ergiebt sich, wie Lazarus, der Verfasser und R. Pfeiffer zeigen konnten, dass, sobald erst einigermaassen ausgesprochene Krankheitserscheinungen aufgetreten sind, trotz stärkster Serumzufuhr der Tod an fortschreitender Infection nicht mehr aufgehalten werden kann. Dasselbe Serum also, das den gesunden Organismus in minimalsten Quantitäten vor der Infection bewahren kann, verliert im kranken Organismus nach einer gewissen Zeit die Fähigkeit, die lebenden Krankheitserreger abzutödten.

Diese biologischen Punkte also sind es, die wir im folgenden näher prüfen wollen, und zwar experimentell mit Hülfe des Serums von Thieren, welche gegen den Bacillus pyocyaneus von mir immunisirt worden waren. Dieses Immunserum eignet sich deshalb insbesondere zum Studium dieser Punkte, weil, wie ich schon oben erwähnte, man in ihm einerseits gleichzeitig antitoxische und bactericide oder andererseits ausschliesslich bactericide Functionen erzielen kann. Man vermag also hier sehr leicht vergleichende Heilversuche mittels dieser beiden verschieden wirkenden Serumarten sowohl gegen Gift als gegenuiber den lebenden Keimen anzustellen. Bevor ich indessen zur Darlegung der bezüglichen Versuche schreite, sei es mir gestattet, auch an dieser Stelle meinem hochverehrten Chef, Herrn Geheimrath $\mathrm{K}_{0 \mathrm{ch}}$, für das warme Interesse, das or denselben stets entgegenbrachte, zu danken.

Die Affection, die man an Meerschweinchen mittels des Pyocyaneus hervorrufen kann, habe ich an anderer Stelle ausfïhrlich beschrieben. Ich will daher hier nur soviel davon recapitulirer als zum Verständniss der nachfolgenden Experimente nöthig ist

Der Verlauf dieser Krankheit ist verschieden, je nachdem wir die Thiere mit den lebenden Pyocyaneusbacillen intraperitoneal inficiren, oder mit sterilem Pyocyaneustoxin vergiften. - Bringt man den Thieren ein Zehntel einer Oese lebender frischer Agarculturmasse in die Bauchhöhle, so vermehren sich die Keime sehr schnell, und es entwickelt sich eine stürmische Peritonitis, wie dies Löffler zuerst beobachtete; die Thiere gehen acut innerhalb 20 Stunden unter Temperaturerniedrigung zugrunde, und in dem Peritonealexsudate der gestorbenen Thiere finden sich alsdann massenhaft lebende Pyocyaneusbacillen. Wählt man die Infection noch stärker, also etwa $1 / 2$ oder ganze Oese, so erfolgt der Tod noch schneller, gewöhnlich nach 8-10 Stunden. Gegen diese tödtliche Infection lassen sich Meerschweinchen mittels des Serums von Thieren, welche gegen den Pyocyaneusbacillus künstlich immunisirt waren, leicht schützen. Es genügt, je nach der Stärke des Serums, $5 \mathrm{mg}$ oder $1 \mathrm{cg}$ Immunserum gleichzeitig mit den Pyocyaneusbacillen zu injiciren, um die letzteren nach einiger Zeit abzutödten und das Thier vor dem Eintritt der Krankheit zu bewahren. Das Serum wirkt also in diesem Falle bactericid. Verwendet man nun aber statt der lebenden Pyocyaneusbacillen das von diesen abgeschiedene, sterile Pyocyaneusgift zum Krankmachen der Thiere, so sehen wir, dass nach intraperitonealer Einverleibung von 1-2 cem eines derartigen Virus die Thiere sehr rasch unter schweren allgemeinen Prostrationserscheinungen erkranken, denen sie nach ca. 8-12 Stunden erliegen.

Will man die Meerschweinchen mittels Immunserums gegen diese Pyocyaneusintoxication schützen, so gelingt dies nicht mit dem oben erwähnten Serum, das von Thieren stammt, die ausschliesslich mittels der lebenden Pyocyaneusbacillen immunisirt worden waren. Es ist dies aber sofort möglich, sobald wir Thiere allmählich mittels Gift immunisiren und deren Serum dann verwenden. Dieses letztere neutralisirt dann, dem Gifte zugemischt, dessen Wirkung und bewahrt die Thiere vor jeder Erkrankung, wirkt also antitoxisch. Indessen sind $\mathrm{zu}$ diesem Zwecke höhere Dosen Serum, nämlich $0,5-1 \mathrm{ccm}$ erforderlich, um gegen die circa vierfache tödtliche Dose Gift zu schützen, während wir gegen die circa 20 fache tödtliche Dose lebender Cultur nur $1 \mathrm{cg}$ benöthigten, wie wir oben sahen. Der Schutz gegen Gift ist also beim Pyocyaneus schwerer zu erzielen, als der gegen lebende Cultur, ganz analog, wie dies Behring in Gemeinschaft mit Boer bereits früher für Diphtherie festgestellt hatte.

Im folgenden wollen wir nun ersehen, wie sich lebende Bacterien und Gift im Organismus verhalten, wenn das Serum erst einige Zeit nach der Intoxication, resp. Infection zur Anwendung kommt, also nicht mehr zum Schutz, sondern bei den bereits erkrankten Thieren zur Heilung angewendet wird. 
Tabelle I. Heilversuche mittels antitoxischen Serums an kranken Thieren, die mit Pyocyaneustoxin vergiftet waren.

\begin{tabular}{|c|c|c|c|}
\hline & & & \\
\hline Meerschwein- & Meerschwein- & Meerschwein- & $\begin{array}{c}\text { Meerschwe } \\
\text { chen IV }\end{array}$ \\
\hline $\begin{array}{l}\text { chen } 1 . \\
\text { April } 1896 .\end{array}$ & 11. April 1896. & 11. April 1896 . & 11. April 18 \\
\hline 1 Uhr Mittags & 1 Uhr Mittags & 1 Uhr Mittags & 1 Uhr Mit \\
\hline 0,75 ecm Pyo- & $0.75 \mathrm{ccm}$ Pyo- & $0,75 \mathrm{ccm}$ Pyo- & $\mathrm{cm} \mathrm{H}$ \\
\hline $\begin{array}{c}\text { cyaneusgift in- } \\
\text { traperitoneal; }\end{array}$ & $\begin{array}{c}\text { cyaneusgift in- } \\
\text { traperitoneal: }\end{array}$ & $\begin{array}{l}\text { cyaneusgift in- } \\
\text { traperitoneal. }\end{array}$ & traperitoneal \\
\hline um 5 Uhr Tem- & um 6 Uhr Tem- & Um 5 Uhr Tem- & 12. April 18 \\
\hline peratur $\quad 35,1$. & peratur $34^{0}$; & peratur $\quad 35,3$. & der \\
\hline $\begin{array}{ll}\text { Thier schwer- } \\
\text { krank; }\end{array}$ & $\begin{array}{l}\text { starke Prostra- } \\
\text { tion ; erhält }\end{array}$ & $\begin{array}{l}\text { Thier schwer } \\
\text { krank: erbält }\end{array}$ & \\
\hline $5 \mathrm{ccm}$ antitoxi- & $6 \mathrm{ccm}$ antitoxi- & $5 \mathrm{ccm}$ normales & \\
\hline $\begin{array}{l}\text { sches Serum } \\
\text { intraperitoneal. }\end{array}$ & sches Serum & Ziegenserum & \\
\hline 12. April, Thier & 12. April. Noch & 12. A pril. Tod & \\
\hline minter. Tem- & etwas krank; & en. & \\
\hline & Zuckungen & & \\
\hline & $1 \mathrm{EW}$ & & \\
\hline & 14. April. & & \\
\hline
\end{tabular}

Aus den vorstehenden Versuchen, die ich öfters mit dem gleichen Resultate wiederholt labe, ersehen wir also, dass es gelingt, schwer vergiftete Thiere mittels der Zufuhr von antitoxischem Pyocyaneusserum zu retten. Dass diese lebensrettende Wirkung eine dem antitoxischen Serum specifische ist, erkennen wir an dem Thier III des obigen Versuchs. Denn die gleiche Menge Serums, das von einer normalen, also nicht gegen das Pyocyaneusgift immunisirten Ziege herrührt, vermochte keinerlei Heilwirkung auszü̈ben. Die specifische Heilwirkung gegenüber dem Gifte lässt sich noch erzielen, wenn bereits mehr als die Hälfte der seit der Intoxication bis zum Eintritt des Todes nöthigen Zeit verflossen ist und die Thiere bereits schwer krank sind. Ich habe es im Hinblick auf den grossen Thierverbraucl unterlassen, genau die Antitoxinmenge zu bestimmen, die gerade noch zur Heilung ausreicht, oder festzustellen, wie lange nach der Vergiftung noch Heilung zu erzielen ist. Da von dem von mir verwendeten Serum $0,5 \mathrm{ccm}$ genügten, $u m$ bei der Mischung mit $1 \mathrm{ccm}$ Gift und gleichzeitiger Injection die Thiere vor der Erkrankung zu schützen, so kann ich also nach dem Ausfall der obigen Versuche jedenfalls das als feststeliend anselien, dass die zehnfache immunisirende Dose bei der Intoxication mit der dreibis vierfachen Dosis certe letalis von Pyocyaneusgift ausreicht, um deutliche Heileffecte zu zeigen. - Es stimmen diese Zahlen fast völlig mit den von Behring bei seinen Heilversuchen an diphtherievergifteten Thieren ermittelten Daten überein. Indessen gilt diese Analogie nur für die drei- bis vierfache Dosis letalis des Pyocyaneusgiftes. Denn während Behring auch bei der Anwendung viel grösserer Mengen des Dîphtlieriegiftes noch Heilung erzielen konnte, ist dies beim Pyocyaneustoxin nicht mögliclı. Die Gründe, worauf dies beruht, habe ich an anderer Stelle bereits auseinandergesetzt. Das Diphtheriegift bietet also der Heilung noch viel bessere Chancen als das lier in Rede stehende Toxin, indem noch stärker gewählte Intoxicationen dort mit dem Serum geheilt werden können.

Nachdem wir im Vorhergehenden das Verhalten des Pyocyaneustoxins gegenüber dem antitoxisch wirkenden Serum in Heilversuchen kennen gelernt haben, wollen wir nunmehr die Heilungsfähigkeit der Infection mit lebenden Pyocyaneusbacillen mittels des bactericiden Serums zu bestimmen suchen.

Tabelle II. Heilversuche mittels bactericid wirkenden Serums an kranken Thieren, die mit Pyocyaneuscultur inficirt waren.

Meerschweinchen I. Meerschweinchen II. 25. September 1896. 25. September 1896. 11 Uhr 45 Minuten Vormittags eine Oese Pyocyaneuscultur intraperitoneal. $12 \mathrm{Uhr}$ 45 Minuten: Thier ist munter; Temperatur 37,9 ; orbält $2 \mathrm{ccm}$ bactericiden Serums, von welchem $0,01 \mathrm{ccm}$ bei gleichzeitiger Injection gegen eine Oese Pyocyaneuscultur schutzt, also die 200-

fache immunisirende Dose.

Nach sechs Stunden nur mehr sehr vereinzelte Pyocyaneusbacillen in Peritoneum.

26. Soptember. Thier munter, lebt.
Die Heilresultate dieser Versuchsreilıe, also gegenüber der Infection, sind, wie wir sehen, viel ungünstiger als die in Tabelle I gegenlïber der Intoxication aufgefülırten. Nur das Thier, das circa eine Stunde nach der Infection in Belandlung genommen wurde, konnte noch gerettet werden, alle späteren, auch wenn sie nur die leichtesten Krankheitserscheinungen zeigten, erlagen der fortschreitenden Infection. Dass etwa nicht eine zu geringe Dose des verabreichten Serums die Ursache des unaufhaltsamen Infectionsfortschrittes war, geht aus dem nachfolgenden Versuche hervor.

$$
\text { Meerschweinchen IV. }
$$

26. September 1896. Erhält $1 \mathrm{ccm}$ Peritonealexsudat des gestorbenen Thieres II aus dem vorigen Versuche $+1 / 2$ Oese lebender Pyocyaneusbacillen intraperitoneal. Nach sechs Stunden Peritoneum steril. Thier lebt, munter.

Also das an der Pyocyaneusinfection gestorbene Meerschweinchen II hatte einen solchen Ueberschuss bactericiden Serums in sich, dass ein Bruchtheil seines Peritonealexsudates stark schützend gegenüber der Infection bei einem frischen Organismus wirkte. Demnach war es nicht Mangel an bactericiden Substanzen, der die Heilung niclit zustande kommen liess, sondern der inficirte Organismus konnte die im Ueberschuss vorhandenen bactericiden Kräfte des Serums nicht mehr verwerthen, während das gesunde Thier dies wieder vermoclite. Es deckt sich dies mit Befunden, die R. Pfeiffer bei Versuchen über die Infection mit Choleravibrionen und deren Beeinflussung durcl das bactericide Choleraserum machte. ${ }^{1}$ )

Ich habe dann weiterhin gegenüber der Infection mit lebenden Pyocyaneusculturen noch Heilversuche mittels eines Serums gemacht, das gleichzeitig antitoxische und bactericide Substanzen enthielt, indessen mit dem nämlichen Resultate, weshalb ich dieselben hier nicht in extenso beifügen will. Es ergiebt sich somit für die Pyocyaneuskrankheit die beim ersten Blick auffallende Thatsache, dass gegenüber denı Gifte, gegen das der Organismus viel schwerer zu immunisiren ist, als gegen die lebenden Bacillen, umgekehrt leichter und länger Heilresultate erzielt werden können als gegenüber der Infection. Dasselbe Factum ist auch bereits von Behring in Gemeinschaft mit Boer bei den Heilversuchen an diphtheriekranken Thieren gefunden worden. -- In der Arbeit "Die Werthbestimmung des Diphtherieheilserums" giebt Beliring in Gemeinschaft mit seinem Mitarbeiter ausdrücklich an, dass es scheint, als ob es mit verhältnissmässig geringerer Steigerung der Serummenge gelingt, diphtherievergiftete Thiere zu heilen, als diplitherieinficirte", während für den vorleerigen Sehutz analog wie beim Pyocyaneus das Umgekehrte von den Autoren nachgewiesen worden war.

Die antitoxischen Kräfte des Immunserums sclieinen sonach im vergifteten Organismus leichter ihre Wirkung gegenüber dem Toxin ausüben zu können, als die bactericiden Körper im inficirten Thiere gegenüber den Bacterien. - Indessen ist diese Heilwirkung des antitoxischen Serums bei der Pyocyaneuskrankleit nach dem bisherigen Ausfalle meiner Versuche eine viel begrenztere als diejenige des Diphtherieantitoxins. Denn wälırend mit dem antitoxischen Diphtherieheilserum Thiere sicher vom Tode gerettet werden können, ob sie nun beispielsweise mit der drei-, zehn- oder zwanzigfach tödtlichen Toxindose vergiftet worden waren, so ist die lebensrettende Wirkung des Pyocyaneusantitoxins nur möglich, falls die vergiftende Dose nicht höher als etwa die vierfache Dosis letalis betrug. Werden höhere Multipla, also etwa die 20 fach tödtliche Menge Gift den Thieren verabreicht, dann ist cine Heilung, auch wenn die Behandlung sofort beginnt und ein grosser Ueberschuss von Antitoxin injicirt wird, mir nie möglich gewesen. Worauf, meiner Meinung nach, dies beruht, habe ich an anderer Stelle auseinanderzusetzen versucht. Demnach sehen wir also, dass schon aus diesem Grunde das Diphtherieantitoxin viel bessere praktische Heilresultate ergeben muss, als ein Antitoxin, das sich so verlält, wie dies soeben vom antitoxischen Pyocyaneusserum beschrieben wurde. - In der That hat der glänzende Erfolg des Diphtherieantitoxins dies zur Genüge bewiesen. Es ergiebt sich also, wie verschieden wirksam sich ein Immunserum bei Heilversuchen verhalten kann, während seine schützenden Eigenschaften sehr ausgesprochen sein können. Das bactericide Pyocyaneusserum z. B. schützt, vorher injicirt, die Thiere in minimalen Quantitäten gegen eine nachfolgende Infection mit der circa zehnfach tödtlichen Dose. Trotzdem giebt es bei Heilversuchen gegenüber derselben vorhergegangenen Infection ungenügende Resultate. Von dem antitoxischen Pyocyaneusserum sind dagegen viel höhere Werthe erforderlich, um gegen die circa drei- bis vierfache Dosis letalis des Giftes zu schützen, umgekehrt dagegen giebt es bei Heilversuchen gegenüber dieser Dose bessere Erfolge als das bactericide. Das Diphtherieserum endlich schützt sowohl als heilt, auch gegenüber

1) Zeitschr. f. Hyg. u. Infectionslirankh. Bd. XIX. 
allen Quantitäten lebender Cultur oder Gift, soweit man bisher untersucht hat, auch noch längere Zeit nach der Infection oder Intoxication, übt also von diesen dreien Arten weitaus die stärkste therapeutische Kraft im Experimente aus.

Wir haben gesehen, dass beim Pyocyaneus der mit lebenden Keimen inficirte Organismus früher die Fähigkeit verliert; die bactericiden Körper zu verwerthen und dadurch geheilt zu werden, als der vergiftete gegenüber den antitoxischen Stoffen. - Es drängte sich nun nach Feststellung dieser Thatsachen die weitere Frage auf, ob in diesem Stadium des inficirten Organismus überhaupt die Fähigkeit erloschen ist, bactericide Körper zu activiren, oder ob dies im gegebenen Augenblick nur für eine bestimmte Art der Fall ist, so dass z. B. eine andere Art bactericider Stoffe von demselben Organismus noch verwerthet werden kann, der für die erste diese Fähigkeit bereits verloren hat.

Um diese Verhältnisse näher $\mathrm{zu}$ studiren, habe ich Thiere gleichzeitig mit der ca. 20 fach tödtlichen Dose lebender Choleraund Pyocyaneusbacillen inficirt. Derartige Thiere sterben nach acht bis zehn Stunden und zeigen dann culturell in ihrem Poritoneum die beiden Arten Mikroorganismen in grossen Mensen neben einander. Ich habe nun versucht, ob in dem Stadium, in welchem nach unseren obigen Experimenten der pyocyaneusinficirte Organismus die Fähigkeit der Verwerthung der bactericiden Stoffe eingebüsst hat, gleichzeitig auch diese Fähigkeit für die bactericiden Stoffe der Cholera verloren gegangen ist. Das zu diesen Versuchen nöthige bactericide Choleraserum stellte mir Herr Prof. R. Pfeiffer in liebenswürdigster Weise zur Verfügung. Dasselbe schützte bei gleichzeitiger Injection in der Dose von $1 / 10 \mathrm{mg}$ gegen eine Oese Choleracultur.

Tabelle III. Meerschweinchen I.

15. October 1896, 11 Uhr 45 Minuten. Eine Oese Choleracultur und gleichzeitig eine Oese Pyocyaneuscultur intraperitoneal.

1 Uhr 45 Min. Temperatur 36,5, im Peritonealexsudate mikroskopisch zahlreiche Pyocyaneus- und Cholerabacillen, erhalt $2 \mathrm{ccm}$ bactericides Pyocyaneusserum und gleichzeitig $2 \mathrm{~cm}$ bactericides Choleraserum, Verdünung 1:100, also von beiden je die 200 fache immunisirende Dose.

Abends gestorben, im Peritoneum nur Pyocyaneus culturell, keine Cholera.

Wir sehen also aus diesem Versuche, dass in dem Stadium, woselbst der inficirte Organismus die bactericiden Stoffe des Pyocyaneus nicht mehr zu activiren vermochte, er dies noch für diejenigen der Cholera konnte. Dass das alleinige Weiterschreiten der Pyocyaneusinfection nicht etwa an dem Umstande lag, dass die zweihundertfach immunisirende Dose wohl für eine Coupirung der Cholera, aber noch nicht für die der Pyocyaneusinfection genügte, geht daraus hervor, dass das in der Leiche vorhandene Peritonealexsudat einen solchen Ueberschuss von bactericiden Körpern zeigte, dass mit einem Theile desselben ein neues Thier vor der Pyocyaneusinfection geschützt werden konnte. Die Quantität des injicirten bactericiden Pyocyaneusserums wäre also jedenfalls ebenso ausreichend gewesen, wie die für die Cholerainfection, die ja noch zum Stehen zu bringen war. Aber der Organismus war trotz der ungefähr gleich starken Infection gegenüber der Benutzung der Pyocyaneusantikörper viel früher ausserstande gesetzt, als gegenüber der der Cholera Das also ist das Interessante an diesem Versuche, dass der unter dem Einflusse einer Infection für die Ausnützung einer Art bactericider Substanzen unfähig gewordene Organismus eine andere Species bactericider Stoffe trotzdem noch zur Heilung verwenden kann, und ferner, dass bei möglichst gleich stark gewählter Infection diese Schädigung desselben bei der einen Affection früher als bei der anderen eintreten kann. Es dürfte sich also hierbei nicht um eine gleichmässige Beeinflussung des Gesammtorganismus handeln, sondern um eine je nach der Infection verschiedene specifische biologische Functionsänderung, die bei Cholerainfection beispielsweise später auftritt, als bei der Pyocyaneusinfection. Wie sich dies bei anderen Infectionen verhält, müssen weitere Versuche ergeben, die dann vielleicht auch über dieses noch unaufgeklärte, für die Frage der eventuellen Serumtherapie mittels bactericid wirksamer Serumarten aber sehr wichtige Kapitel mehr Licht verbreiten werden.

Werfen wir also einen Rückblick auf die in unseren Versuchen gewonnenen Thatsachen, so sehen wir vor allem, dass die Therapie der Intoxication mittels des antitoxischen Serums bedeutend bessere Resultate giebt, als die der Infection mittels bactericiden Serums. Woran dies liegt, lässt sich mit Sicherheit heute noch nicht entscheiden. Sehr wichtig dafür scheint mir jedenfalls der von Behring und seinen Mitarbeitern, Wernicke und Knorr in neuester Zeit erhobene Befund zu sein, dass bei den für Tetanusgift empfindlichen Thierspecies sowohl Toxin als auch Antitoxin lange Zeit fast ausschliesslich im Blute circuliren, ohne in den Organen festgehalten zu werden. Wir sehen also aus alledem, wie verschieden sich ein Serum, das deutlich schützende Eigenschaften im Thierversuche zeigt, bei Heilexperimenten verhalten kann und dass demnach der Immunisirungswerth cines Serums noch durchaus keinen sicheren Rilickschluss auf den Heilwerth gestattet; ein Punkt, den Behring stets mit Recht und Nachdruck hervorgehoben hat. Um so bedauerlicher ist es unter diesen Umstånden, wenn in neuester Zeit nach einem Immunisirungsschema Serumarten gegen alle möglichen Krankheiten hergestellt und ohne die so nothwendigen exacten Thierversuche sofort am Menschen versucht und verbreitet werden. Es kann dieses voreilige schematische Verfahren durch seine unausbleiblichen Misserfolge nur dazu führen, diese wirklich exact experimentell gefundene, bei Diphtherie so erfolgreiche specifische Heilmethode, die wir durch Behring besitzen, bei der grossen ärztlichen Welt, die diese Einzelheiten nicht so verfolgen kann, zu discreditiren. 